\title{
Trajetória da Avaliação da Educação Superior no Brasil: singularidades e contradições (1983-2004)
}

\author{
ANDRÉA BARBOSA GOUVEIA \\ Professora da Universidade Federal do Paraná (UFPR); Doutoranda em Educação \\ na Faculdade de Educação da Universidade de São Paulo (Feusp) \\ andreabg@ufpr.br \\ ANTONIA ALMEIDA SILVA \\ Professora da Universidade Estadual de Feira de Santana - BA (Uefs-BA); \\ Doutoranda da Feusp \\ antonia@uefs.br \\ ADRIANA A. DRAGONE SILVEIRA \\ Pedagoga; Mestranda da Feusp \\ adrianadragone@yahoo.com.br \\ MÁRCIA APARECIDA JACOMINI \\ Professora do curso de Pedagogia da Faculdade Taboão da Serra (FTS); \\ Psicopedagoga; Doutoranda da Feusp \\ marciajacomini@uol.com.br \\ TEREZINHA PEREIRA BRAZ \\ Professora da União da Associação Educacional Sul Mato-grossense (Unaes) - \\ Faculdade de Campo Grande; Doutoranda em Educação da Feusp \\ terebraz@terra.com.br
}

\begin{abstract}
Resumo
Este artigo recupera a trajetória da avaliação externa de cursos de graduação no Brasil nas últimas duas décadas e tem como objetivo identificar os mecanismos utilizados pelo Ministério da Educação para a construção do sistema nacional de avaliação da educação superior. Para isso, recorre à análise dos processos de formulação das propostas e das experiências de avaliação implantadas no Brasil, revisitando o debate dos anos 1980 com a discussão e apresentação do Programa de Avaliação da Reforma Universitária (Paru), do Grupo de Estudos da Reforma da Educação Superior (Geres) e do Programa de Avaliação Institucional das Universidades Brasileiras (Paiub), e formulando uma interpretação do Exame Nacional de Cursos - "Provão" (1995-2003) e dos desafios postos ao Sistema Nacional de Avaliação da Educação Superior (Sinaes), implantado em 2004. O resgate desse debate permitiu observar, por um lado, que a questão da avaliação é um tema antigo no
\end{abstract}


Brasil e, por outro, que os debates em torno dele são marcados por disputas entre uma concepção de avaliação regulatória, que valoriza o produto das avaliações com vistas à constituição de uma racionalidade típica do mercado, e uma concepção de avaliação formativa, que valoriza o processo de avaliação com vistas ao fortalecimento da função social das instituições de ensino superior a partir de sua missão.

Palavras-chave: política educacional, avaliação, educação superior.

\title{
Resumen
}

En este artículo se trata de recuperar la evaluación externa de cursos de graduación en el Brasil en las últimas dos décadas. Se pretende identificar los mecanismos utilizados por el Ministerio de la Educación para la construcción del sistema nacional de evaluación de la enseñanza superior. A través del análisis de las propuestas y experiencias de evaluación implementadas en el Brasil, el estudio vuelve al mismo debate de los años 80 con la presentación del Paru - Programa de Evaluación de la Reformulación Universitaria, del Geres - Grupo de Estudios de la Reformulación de la Educación Superior y del Paiub Programa de Evaluación Institucional de las Universidades Brasileñas. Formula una interpretación del Examen Nacional de Cursos - "Provão" (1995-2003) y de los desafíos presentados al Sinaes - Sistema Nacional de Evaluación de la Educación Superior, implementado en 2004. El rescate de tal debate ha permitido observar, por un lado, que la cuestión de evaluación es antigua en el Brasil y, por otro lado, que los debates sobre dicho tema están marcados por disputas entre una concepción que valora las conclusiones y tiene como objetivo la constitución de una racionalidad típica del mercado, y una concepción de evaluación formativa, que valora el proceso con vistas a fortalecer, a partir de su misión, la función social de las instituciones de enseñanza superior.

Palabras-clave: política educativa, evaluación, educación superior.

\begin{abstract}
This article recovers the history of external assessment for higher education courses in Brazil over the last two decades, and aims at identifying the mechanisms used by the Department of Education to build a national assessment system of higher education. For this purpose, we analyze the development of assessment proposals and experiences implemented in the country by looking at the debate that took place in the eighties involving the University Reform Assessment Program, the Study Group for Higher Education Reform, and the Institutional Assessment Program of Brazilian Universities. We also propose an interpretation for the National Courses Exam held between 1995 and 2003, and the challenges brought about by the National System for Higher Education Assessment created in 2004. An overview of this debate has allowed us to observe, on the one hand, that assessment is an old issue in Brazil and, on the other, that the discussion regarding assessment is marked by a controversy between a regulatory concept of assessment, which values the assessment product, seeking the development of a typical market rationality, and a formative concept of assessment, which values the assessment process, aiming at strengthening the social function of higher education institutions.
\end{abstract}

Key words: education policy, assessment, higher education. 


\section{INTRODUÇÃO}

A avaliação tem-se destacado como elemento central do amplo processo de reforma da educação brasileira. Tal ênfase é tanto legal - pois a LDB $n^{\circ}$ 9.394/96 indica que cabe à União a organização de um sistema nacional de avaliação da educação básica e do ensino superior - quanto de cultura política, pois, nos anos 1990, aprofunda-se a disputa em torno de diferentes concepções de avaliação e, principalmente, o poder público implementa sistemas nacionais de avaliação independentemente da legislação em discussão.

Entretanto, o debate acerca da importância da avaliação e sobre as formas para sua implementação já se haviam tornado destaque nos anos 1980. Tal debate foi introduzido, no âmbito científico e acadêmico, com a finalidade de se buscar um entendimento e uma crítica dos padrões de qualidade da educação no país. Naturalmente, não se pode compreender de forma crítica esses padrões sem que a avaliação seja tratada nos marcos da globalização, incluindo a importação de modelos adotados pelo Estado brasileiro e a articulação entre a concepção de política educacional e a compreensão de qual o papel do Estado na implementação dessa política.

Vários autores, dentre eles Dale (2001) e Sousa e Oliveira (2003), têm chamado a atenção para as novas formas de intervenção do Estado na educação dentro do processo de globalização. A globalização é definida por Dale (2001) como um fenômeno complexo e freqüentemente contraditório, construído por meio de três conjuntos de atividades (econômicas, políticas e culturais), relacionados entre si e centralizados em três principais grupamentos de Estados: Europa, América e Ásia, tendo como grande eixo a procura do lucro. Para esse autor, a globalização é diferente de qualquer outra tentativa de organização econômico-político-cultural experimentada anteriormente, porque permite falar de uma economia global que inclui todas as nações. Contudo, observa Dale (2001):

"[...]os agrupamentos regionais partilham a preocupação com o controle $e$ concordam sobre certas regras do jogo. Competem ferozmente para fazer avançar o conjunto de acordos globais que thes seja mais favorável, mas reconhecem que, em última análise, dependem da existência de um mundo que seja seguro para o prosseguimento da procura do lucro e não de um mundo que seja seguro para perseguir o seu lucro próprio a expensas de outros." (p.147)

Dentro desse marco da globalização, a idéia de desregulamentação foi freqüentemente contraposta à idéia de intervenção estatal, tendo por base a crítica ao modelo do Estado provedor e a defesa da diversificação 
institucional inspirada na lógica da transposição dos valores e dinâmicas do mercado.

O Estado, sob o ideário em questão, desloca seu patamar de intervenção nas políticas sociais da manutenção dos serviços para, predominantemente, a fiscalização. Essas mudanças, observadas por Levin (2001) a partir dos anos 1970 na Inglaterra, Estados Unidos e Canadá, manifestam-se no Brasil de forma mais contundente a partir dos anos 1990, quando a flexibilidade e a competitividade passam a compor as plataformas governamentais sob o signo da reforma do Estado. A partir de então, as críticas dirigidas à educação põem em relevo a premência da diversificação das políticas educacionais e os novos papéis do Estado e da sociedade ante as políticas educacionais. Oliveira (2000) mostra que nesse processo a marca das reformas educacionais é sua natureza bipolar: por um lado, a centralização da avaliação e o controle do sistema e, por outro, a descentralização de gestão e financiamento.

No âmbito da educação superior, essas mudanças tomaram força, particularmente, a partir do diagnóstico que incluía como problemas principais, a serem enfrentados para a adequação do sistema às novas exigências, as seguintes questões:
“a) esgotamento do modelo único baseado na indissociabilidade ensino- pesquisa-extensão;
b) tamanho do sistema extremamente modesto para as dimensões $e$ necessidades do país;
c) inadequação do processo de credenciamento de novas instituições, o que gerou um sistema sem competição e de baixa qualidade;
d) falta de um sistema abrangente de avaliação do ensino de graduação;
e) desafio de modernizar o ensino de graduação;
f) ineficiência no uso dos recursos públicos na parte federal do sistema." (Catani, Oliveira, 2000, p. 108-109)

Com base nesse diagnóstico, uma das frentes prioritárias da política governamental foi a da avaliação. Esta, como um dos pilares para o enfrentamento dos problemas referidos, desde muito cedo passou a ser enfocada segundo a tradição do accreditation. Nessa tradição, a avaliação é defendida como um processo muito positivo, que não só faz análises e diagnósticos, mas cria oportunidades de discussão e de reflexão dos problemas institucionais. Dentro dessa perspectiva acredita-se, ou faz-se acreditar, que a integração de diferentes procedimentos de avaliação permitirá a análise dos pontos fortes e fracos da instituição e, uma vez detectados esses pontos, a instituição será estimulada a discutir os problemas e as providências para promover melhorias. Há uma certa 
confiança de que a qualidade e os standards ${ }^{1}$ dos títulos da educação superior sejam garantidos e ampliados, focando a qualidade das oportunidades de aprendizagem oferecidas, os padrões acadêmicos alcançados e os sistemas de garantia de qualidade existentes nas instituições de educação superior (IES). Nessa perspectiva, a defesa dos procedimentos de avaliação sugere uma relação direta entre accreditation e qualidade. Verifica-se, com isso, como adverte Oliveira (2000), a substituição das funções intermediárias do Estado, de inspeção e supervisão, por um controle do produto final, dentro de um esforço de disseminar uma cultura de avaliação, no sentido de criar uma expectativa de que os resultados e a pressão dos usuários induzam a busca por melhor qualidade.

Outra dimensão bastante explorada, no âmbito do debate sobre avaliação, é a da sua defesa como accountability, isto é, responsabilização e prestação de contas dos recursos públicos que foram utilizados. Em que pese a relevância dessa prática, como lembra Dias Sobrinho (2002), isso não tem uma intencionalidade socioeducativa propriamente, mas antes se apresenta como controle expresso em termos técnicos para, supostamente, assegurar a objetividade e excluir a possibilidade de questionamentos. Dessa forma, essa avaliação educacional é posta com esmerada sofisticação técnica para atender às demandas do Estado contemporâneo, gestor e portador de uma racionalidade empresarial mais refinada, que não poupa esforços para se adequar às modificações ocorridas na produção, destacando-se a avaliação na educação como uma forma de racionalizar recursos, alcançar a qualidade defendida pelo mercado, controlar e coletar indicadores para a tomada de decisões políticas de desenvolvimento da educação superior.

Com base nessas referências iniciais, este artigo recupera a trajetória da avaliação externa na graduação no Brasil, nas últimas duas décadas, e tem como objetivo identificar os mecanismos utilizados pelo Ministério da Educação (MEC) para a construção do Sistema Nacional de Avaliação da Educação Superior. Para isto, buscar-se-á indicar as primeiras iniciativas de fomento da avaliação da educação superior, identificadas no Programa de Avaliação da Reforma Universitária (Paru), passando por uma breve apresentação do Grupo de Estudos da Reforma da Educação Superior (Geres) e do Programa de Avaliação Institucional das Universidades Brasileiras (Paiub). Em seguida, apresentar-se-á o Exame Nacional de

1 Standard: refere-se aos resultados alcançados pelos alunos e à educação necessária para garantir que esses resultados sejam efetivamente alcançados. Deve resumir o que um empregador esperaria de uma pessoa que se formasse em qualquer área, em qualquer disciplina (Brasil, 2001, p. 11-12). 
Cursos - "Provão", momento em que a avaliação do ensino superior toma corpo e publicidade; por fim, analisar-se-á a aprovação do Sistema Nacional de Avaliação da Educação Superior (Sinaes).

Por ora, vale observar que, na trajetória da avaliação superior, desde muito cedo se reconhece a complexidade do sistema de educação no nível superior e de sua avaliação, ainda mais quando se considera a diversidade de concepções e de interesses que perpassa essa avaliação. Sem dúvida, isto tem permitido o avanço dos debates e da produção na área, mas também tem fomentado a descontinuidade das propostas e até mesmo a duplicidade das mesmas, como no caso específico do Paiub, que não chegou a ser extinto, mas também não era estimulado, ou melhor, não era sequer referido. Tais fatos podem-se constituir não só em inibidores de possíveis metavaliações das práticas experimentadas, mas também em referências negativas para a construção de uma cultura avaliativa, como se verá a seguir.

\section{PARU, GERES E PAIUB: PRIMEIRAS INICIATIVAS}

O Paru constitui um marco na trajetória da avaliação da educação superior. Iniciado em 1983, é tido por Cunha (2001) como a primeira pesquisa nacional sobre a gestão das universidades brasileiras, e surgiu como um contraponto ao sistema de avaliação da pós-graduação implantado pela Coordenação de Aperfeiçoamento Profissional do Ensino Superior (Capes) em meados da década de 1970. Originado sob os auspícios da própria Capes, o Paru foi concebido como um mecanismo para apontar à graduação em que medida a reforma universitária instaurada com a Lei $\mathrm{n}^{\circ}$ 5.540/68 "realmente se efetivou, quais as vantagens alcançadas e quais os problemas enfrentados pelos diversos tipos de curso e de instituições" (Cunha, 2001, p. 126).

Citando o referencial teórico do estudo base do Paru, o autor diz tratar-se de um documento avesso ao tecnicismo e que, segundo o próprio documento, busca

"[...] apreender o ethos de cada instituição, principalmente por intermédio de uma análise histórica que, partindo da atual situação da IES, permita chegar à recuperação de sua trajetória, em relação a processos tais como maneira de legitimação das decisões internas, modos específicos de gestão e formas de tomada de decisão. Tais processos interferem na formulação de políticas concretizadas em diferentes tipos de práticas acadêmicas que, assim, expressam a marca política da instituição." (apud Cunha, 2001, p. 27, grifos do autor) 
Embora esse programa não tenha chegado a se estabelecer como um programa nacional de avaliação, sendo desativado em 1984, ele acenava para a (re)organização do sistema de educação superior a partir da coleta e análise de dados sobre a gestão das IES e a produção e disseminação de conhecimentos em face da reforma instituída pela Lei $\mathrm{n}^{\circ}$ 5.540/68.

Em 1985, foi criada a Comissão Nacional de Reformulação da Educação Superior, a qual apresentou ao MEC seu relatório final, intitulado Uma nova política para a educação superior brasileira (Brasil, 1985), em novembro do mesmo ano. Embora essa comissão não tivesse como tarefa avaliar o sistema de educação, não deixou de se referir ao assunto, indicando em seu relatório a necessidade do então Conselho Federal de Educação de "estabelecer mecanismos de avaliação permanente do sistema brasileiro de educação, com apoio de comissões ad hoc de especialistas por ele designados" (Brasil, 1985, p. 50).

Tal iniciativa ajustava-se à necessidade constatada pela comissão do ensino superior ${ }^{2}$ brasileiro de, por um lado, reforçar a convivência e o mérito acadêmicos e, por outro, estabelecer padrões que servissem de parâmetro aos vários segmentos implicados com esse nível da educação.

"A ausência de parâmetros afeta o ensino superior sob muitos pontos de vista. Para o governo, ela não permite que se tenha uma política racional de alocação de recursos públicos que fortaleça as melhores instituições e induza as demais ao aperfeiçoamento. Para professores e administradores educacionais, ela impede que saibam exatamente como melhorar suas instituições, quais os falsos caminhos, quais as soluções mais promissoras. Para o candidato à universidade e sua família, a escolha de uma escola superior e de uma profissão é como uma loteria: os alunos decidem suas carreiras baseados em fragmentos de informação, o que explica, em parte, a grande frustração e um certo ceticismo que acabam permeando o sistema universitário do País." (Brasil, 1985, p. 52)

Nota-se que no relatório a avaliação figurava como importante aspecto a ser considerado para o sucesso da reforma da educação superior a ser realizada, constituindo um mecanismo de controle institucional tanto interno quanto externo, com vistas à apreensão do mérito das IES por meio do desempenho de seus agentes. $\mathrm{O}$ relatório apresentava uma ênfase explicitamente regulatória de avaliação e a valorização do mérito individual no processo de redirecionamento da política para a educação superior naquele momento. No documento, defendia-se uma concepção de universidade, apresentava-se um conjunto de medidas para a reforma da educação superior, formulavam-se diretrizes para as políticas educacionais, embora não fossem apresentadas referências explícitas a quaisquer fontes,

2 A comissão usa o termo "ensino superior" em vez de "educação". 
exceto aos modelos de regulação institucional como, por exemplo, o Scholastic Aptitude Test (Estados Unidos).

A partir desse relatório, foi constituído o Geres, cuja tarefa era dar conseqüência ao relatório produzido pela Comissão Nacional de Reformulação da Educação Superior. Embora o Geres não tenha chegado à realização da reforma universitária, e menos ainda a uma política para a educação superior, a literatura sobre a avaliação da educação superior nos anos 1980 (Cunha, 2001; Dias Sobrinho, 2002; Brasil, 2003) indica a importância do relatório e do próprio Geres para a estruturação da política de avaliação da educação superior que se efetivou a partir da Lei $\mathrm{n}^{\circ}$ 9.131/95, cujo desdobramento mais visível foi a implementação do Exame Nacional de Cursos, como se verá adiante.

Outro dado importante, na seqüência dos esforços empreendidos para a consolidação de uma cultura avaliativa na educação superior, foi o Encontro Internacional sobre Avaliação do Ensino Superior, realizado em 1987, em Brasília, promovido pela Secretaria da Educação Superior (SESu) do Ministério da Educação, com o apoio da Organização dos Estados Americanos (OEA). Esse evento inseriu-se na programação de estudos relativos a essa matéria, visando a obter contribuições para a realidade brasileira (Brasil, 1988)3. Embora o mesmo não tenha adquirido a visibilidade dos documentos acima referidos, o conteúdo dele é muito expressivo para a compreensão dos contornos das propostas de avaliação que vieram a se consolidar posteriormente. Aliás, os anais, publicados em 1988, já reconheciam que

"[...] a partir da realização daquele Encontro ampliou-se o número dos que passaram a interessar-se pela problemática da avaliação $e$ abriram-se perspectivas novas e interessantes que passaram a ser exploradas de forma mais intensa por significativa parcela de docentes e administradores das instituições de ensino superior do país." (Brasil, 1988, p. 5, grifo nosso)

O evento representou não só um momento de estudo e aproximação com outras experiências, mas também uma oportunidade de envolvimento de docentes e administradores e de alargamento das perspectivas de avaliação da educação. Já ali os resultados das avaliações (que ainda não

\footnotetext{
3 Os dois primeiros dias do encontro foram voltados para a análise de modelos já implementados (Inglaterra, França, Canadá e Japão) e os dias seguintes priorizaram o amadurecimento de discussões em grupos de trabalho, sendo que cada grupo enfocou um tema específico: avaliação de sistemas de ensino superior, avaliação de desempenho das IES, avaliação da qualidade do ensino, conseqüências e impactos de avaliação. Os grupos foram coordenados, respectivamente, por: Eunice Durham (USP), Simon Schwartzman (Iuperj), José Torquínio Prisco (UFCE) e Oscar Serafini (UnB).
} 
existiam) eram projetados como fatores para discriminar a alocação de recursos públicos. Embora se negue o estabelecimento de qualquer vinculação entre formas de avaliação e a distribuição de recursos para as instituições públicas, para aquele momento admitia-se que as instituições privadas viessem a ter acesso aos recursos públicos a partir das avaliações. E mais, "que a longo prazo, um sistema novo e global de avaliação venha gradativa e voluntariamente permitir a utilização de seus resultados como critérios de alocação de recursos por órgãos públicos" (Brasil, 1988, p. 10). Esta indicação, assumida na introdução dos anais do evento, partiu do grupo de trabalho Conseqüências e Impactos da Avaliação, em sua análise sobre a distribuição de recursos.

Apesar de tão ingrata expectativa, ficou claro que a avaliação da educação superior seria inadiável. Os resultados desse mesmo grupo de trabalho revelam bem isso ao recomendarem aos órgãos federais que "estimulassem qualquer tipo competente de experiências avaliativas, promovendo uma cooperação técnica interinstitucional" (Brasil, 1988, p. 45). Tal formulação leva a observar que, de fato, aqueles senhores não estavam interessados em construir a "melhor avaliação" ou a "mais adequada", mas em pôr em ação procedimentos de avaliação, independentemente do modelo e/ou concepção.

No início dos anos 1990, o debate sobre avaliação ganha contornos mais sólidos com a proposta do Paiub. Esse programa, oriundo de uma comissão de especialistas, "foi desenvolvido sob a coordenação de uma Comissão Nacional de Avaliação, com a participação majoritária de associações de dirigentes universitários e de representantes do governo vinculados à SESu" (Brasil, 2003, p. 24).

Como primeira iniciativa a se efetivar, o Paiub logrou o envolvimento de IES e a promoção de uma cultura de avaliação no interior das instituições (Sousa, Oliveira, 2003), constituindo um marco na trajetória da avaliação superior. Esse programa partia do entendimento de que o contraponto entre o pretendido e o realizado é que dá sentido à avaliação. Defendia que o processo de avaliação das IES deveria atender a uma tripla exigência da universidade contemporânea:

“a) um processo contínuo de aperfeiçoamento do desempenho acadêmico;

b) uma ferramenta para o planejamento e gestão universitária;

c) um processo sistemático de prestação de contas à sociedade." (Brasil, 1993, p. 4)

A diferença entre essa proposta e as indicações do documento base do Geres é sensível. Enquanto a primeira parte de uma perspectiva formativa, em que cada IES se avalia e é avaliada considerando suas 
características e as finalidades do projeto institucional, a segunda aproxima-se de uma perspectiva regulatória de avaliação com ênfase, por um lado, na verificação de desempenho dos agentes implicados em cada instituição (alunos, professores, técnicos e administradores) e, por outro, no estabelecimento de padrões que sirvam de parâmetros de qualificação das instituições.

Quanto aos objetivos, tanto o Paiub quanto o documento base do Geres articulam a avaliação à busca da qualidade. A avaliação de desempenho da universidade brasileira, diz o primeiro,

"[...] é uma forma de rever e aperfeiçoar o projeto acadêmico e sociopolítico da instituição, promovendo a permanente melhoria da qualidade e pertinência das atividades desenvolvidas. A utilização eficiente, ética e relevante dos recursos humanos e materiais da universidade traduzida em compromissos científicos e sociais, assegura a qualidade e a importância dos seus produtos e a sua legitimação junto à sociedade." (Brasil, 1993, p. 5)

A comparação desses documentos, no entanto, é um tanto superficial, uma vez que só o Paiub efetivamente estruturou uma proposta de avaliação, estabelecendo uma concepção clara, objetivos, estratégias de desenvolvimento e indicadores.

Dias Sobrinho (2002) observa que

"[...] a matriz conceitual e teórico-metodológica do Paiub apresenta algumas semelhanças com os modelos de avaliação produzidos a partir de meados dos anos 1960 nos Estados Unidos, que valorizam a participação e a negociação, elevadas ao campo científico pela fenomenologia social, antropologia, etnografia, hermenêutica e várias outras disciplinas de linhagem das ciências sociais que valorizam as metodologias qualitativas, as abordagens naturalistas, os significados, os contextos e os processos." (p.53)

Em que pese a importância dessa iniciativa na trajetória da avaliação da educação superior, o Paiub foi colocado de lado em 1995, ascendendo, em seu lugar, outro projeto de concepção distinta: o ENC.

\section{EXAME NACIONAL DE CURSOS - PROVÃO}

O governo Fernando Henrique Cardoso implantou o Exame Nacional de Cursos (ENC), mais conhecido como Provão, com uma dimensão pública até então nunca dada à avaliação das instituições de ensino superior. 
A mudança do Conselho Federal de Educação (CFE) para Conselho Nacional de Educação (CNE) por meio da MP n ${ }^{\circ}$ 661, de 18 de outubro de 1994, e a redefinição de suas competências por meio da MP nº 967, de 12 de abril de 1995, foram medidas importantes na montagem do sistema de avaliação do ensino superior. A MP de 1995 criou, inclusive, o Exame Nacional de Cursos, regulamentado definitivamente pela Lei $n^{\circ} 9.131$, de 24 de novembro de 1995. De acordo com essa lei, o CNE não teria competência para realizar a avaliação, devendo apenas deliberar sobre a autorização, credenciamento e recredenciamento, de acordo com relatórios e avaliações elaborados pelo MEC (art. $9^{\circ}, \S 2^{\circ}$, alínea " $\mathrm{e}^{\prime \prime}$ ). O artigo $3^{\circ}$ da Lei $\mathrm{n}^{\circ} 9.131$ definiu como o MEC deveria realizar a avaliação, indicando duas espécies de avaliação: a das instituições e a dos cursos. Seus sete parágrafos tratam dos procedimentos para a avaliação dos cursos, cujo instrumento principal foi o ENC4. Este consistiu no primeiro exame nacional de natureza censitária realizado por alunos concluintes dos cursos de graduação ${ }^{5}$ a partir de 1996. Apesar de o sistema de avaliação do ensino superior no governo do presidente Fernando Henrique Cardoso possuir diversos mecanismos de avaliação das IES, como a Avaliação das Condições de Oferta de Cursos de Graduação (ACO), a Análise das Condições de Ensino (ACE) e a Avaliação Institucional dos Centros Universitários (Catani; Oliveira, 2000), foi o ENC que se tornou o instrumento por excelência de avaliação.

O ENC era constituído por dois instrumentos aplicados aos estudantes:

4 O ENC ainda teria regulamentação complementar da Portaria MEC n ${ }^{\circ}$ 249/96, que instituiu a sistemática para a realização do ENC, e do Decreto $n^{\circ} 2.226 / 96$, que estabeleceu procedimentos para o processo de avaliação dos cursos e instituições de ensino superior. A LDB $\mathrm{n}^{\circ}$ 9.394/96 define que a regulação do ensino superior (art. $9^{\circ}$, inciso IX) é competência da União, nos seguintes termos: “a autorização e o reconhecimento de cursos, bem como o credenciamento de instituições de educação superior, terão prazos ilimitados, sendo renovados, periodicamente, após processo regular de avaliação" (art. 46). Tal indicação ainda foi complementada com o Decreto $n^{\circ}$ 3.860/01, que dispôs sobre a classificação das instituições de ensino superior, entidades mantenedoras, IES e organização acadêmica, avaliação e procedimentos operacionais, o que alterou a organização do sistema federal de ensino (especialmente do Inep e da SESu), afetando igualmente os outros entes do sistema (IES) (Brasil, 2003, p. 34). Este longo processo de regulamentação foi constituindo a concepção do ENC. Para o MEC, este tem como finalidade orientar as suas ações, estimulando e provocando iniciativas para a melhoria da qualidade do ensino, principalmente no que diz respeito à elevação da qualificação dos docentes e à sustentação das deliberações do $\mathrm{CNE}$ na renovação periódica dos cursos de graduação (Brasil, 2003).

5 Inicialmente, o exame foi aplicado em alunos do último ano das graduações em Administração, Direito e Engenharia Civil, expandindo-se a cada ano para outros cursos, até o seu fim em 2003, com a criação dos Sinaes. 
"1. Teste de conhecimentos, por meio de aplicação de provas compostas de questões de múltipla escolha e de questões discursivas;

2. Conjunto de questionários: questionário-pesquisa e questionário sobre impressões das provas. "6 (Brasil, 2003)

A grande repercussão pública do ENC, que em 1996 incluiu 26 cursos, pode ser atribuída a algumas características de sua implementação: o exame sujeitava os alunos formandos dos cursos avaliados à realização obrigatória de uma prova de conhecimentos; as instituições eram classificadas em um ranking, de acordo com os resultados das provas realizadas por seus estudantes, por meio de cinco menções (A, B, C, D e E); os resultados focavam os cursos de graduação e eram registrados no histórico escolar do estudante. Nesses moldes, o exame repercutiu na opinião pública, tanto positiva quanto negativamente, principalmente porque a ênfase na divulgação dos resultados recaía sobre as notas obtidas nas provas, desprezando-se as informações obtidas a respeito dos estudantes ou sobre as próprias provas.

Por outro lado, ao optar por instrumento de avaliação que por sua própria simplicidade tem um caráter bastante restrito, o governo Fernando Henrique parece ter-se preocupado mais em disseminar e legitimar uma cultura de avaliação do que propriamente diagnosticar as diversas facetas do ensino superior brasileiro. Se o objetivo foi esse, pode-se dizer que o governo obteve relativo sucesso, pois, embora as críticas ao ENC como instrumento de avaliação fossem muito numerosas, observaram-se poucas discordâncias a respeito da necessidade de um sistema de avaliação em larga escala para o ensino superior brasileiro, dada a trajetória desse debate no conjunto das IES, já destacado anteriormente.

A implantação do ENC nos anos 1990 enquadra-se em uma política de descentralização da gestão e financiamento da educação articulada com

6 O questionário-pesquisa era enviado aos graduandos antes da realização do exame "para colher informações socioculturais do grupo de graduandos e suas expectativas, bem como para caracterizar os cursos, a partir do ponto de vista de seus concluintes, quanto a recursos e instalações disponíveis, estrutura curricular e desempenho docente" (Brasil, 2003, p. 58). O questionário de impressões sobre a prova era entregue aos graduandos que participavam do exame, durante a realização da prova: "Permite conhecer a opinião dos participantes a respeito do instrumento aplicado, buscando colher informações para o aperfeiçoamento das provas, no que tange à clareza e objetividade dos enunciados, adequação das informações fornecidas para a resolução das questões, adequação do tempo para a realização da prova e o nível de dificuldade e extensão da prova" (Brasil, 2003, p. 58-59). 
a centralização dos processos de avaliação. O governo passou a ter um papel regulador e a avaliação adquiriu o papel de indutor do sistema, das diretrizes políticas desejadas. O próprio Inep explicitava isso ao declarar:

"[...] embora o ENC pretenda apreender os conhecimentos e competências adquiridos pelos alunos que estão em vias de concluir o curso de graduação, o objetivo principal é avaliar os cursos de graduação das IES e utilizar essas avaliações como um dos instrumentos de regulação do sistema de educação superior." (Brasil, 2003, p. 57-58, grifos nossos)

Essa perspectiva foi dada claramente pela então presidente do Inep, Maria Helena de Guimarães Castro. Em 2000, ela apresentava como desafios do ENC "continuar a expandir o sistema de ensino superior e a diversificar a oferta, mas sem perder a qualidade" e "garantir essa expansão com menor controle burocrático por parte do governo e com mais ênfase em indicadores de desempenho" (Brasil, 2001, p. 34).

Além dos instrumentos de avaliação, o governo produziu censos anuais, com indicadores quantitativos globais que forneceram estatísticas sobre a evolução do sistema e a situação de cada instituição de ensino superior.

De acordo com o documento elaborado pelo Inep em 2003, a avaliação se realizava como atividade técnica, buscando medir os resultados produzidos pelas instituições em termos de ensino e também de pesquisa e prestação de serviços à comunidade (Brasil, 2003). Esse modelo de avaliação teria como destaque indicadores quantitativos:

"[...] medidas físicas, como área construída, titulação dos professores, descrição do corpo docente, discente e servidores, relação dos servidores, dos produtos, das formaturas, volumes de insumos, expressões numéricas supostamente representando qualidades, como no caso de números de citações, muitas vezes permitindo o estabelecimento de rankings de instituições, com sérios efeitos nas políticas de alocação de recursos financeiros e como organizador social de estudantes e de profissionais." (Brasil, 2003, p. 14)

Ao mesmo tempo que estimularam os rankings das universidades, os resultados do ENC provocaram ameaça de fechamento automático de cursos para os que obtivessem D e E nos últimos três provões, conforme previsto na Lei $\mathrm{n}^{\circ}$ 9.131, embora raramente a ameaça tenha sido cumprida. Segundo Catani e Oliveira (2000), essa sistemática trazia implícita a idéia de que "o sistema educacional deve ser competitivo e que, para tanto, é preciso instituir um sistema de incentivos e punições, uma vez que tal sistema operaria na direção da promoção da eficiência, do desempenho e da produtividade" (p. 116). 
Assim, em lugar de uma avaliação com ênfase no apoio e na "recuperação" dos cursos e das instituições em dificuldades, consolidou-se uma avaliação de caráter punitivo, como tem sido assinalado por grande parte dos críticos desse modelo. $\mathrm{O}$ uso coercitivo da avaliação, revelado pela adoção de estratégias comuns a todas as instituições, gerou também alguns vícios institucionais como os "preparatórios para o Provão", espécie de cursinho que tinha como objetivo garantir um bom desempenho dos alunos no exame, ou a concessão de "bolsas" e benefícios visando atrair estudantes de quem se julgava poder obter um escore elevado no exame seletivo.

As estratégias adotadas pelas instituições para driblar os rótulos negativos impingidos pelo Provão certamente não tinham qualquer relação necessária com a melhoria da qualidade de ensino. No entanto, parece que esse desvio tendia a elevar o escore das instituições privadas em relação às instituições públicas. Some-se a isso o boicote empreendido por estudantes de universidades públicas uma vez que, do ponto de vista de quem observa apenas os resultados, o ENC valorizava artificialmente as instituições privadas em detrimento das públicas. Isso pode ser observado claramente em reportagem da revista Veja de 31 de março de 2004 na qual se analisam os resultados dos provões de 260 instituições em 26 áreas. Um dado muito significativo é que, entre as dez melhores instituições elencadas em muitos cursos, estavam incluídas instituições que, exceto as notas do Provão, não são amplamente conhecidas por sua qualidade. Ao mesmo tempo, estavam excluídas instituições tradicionalmente tidas como de alta qualidade de ensino em suas áreas. Isso torna claro que uma avaliação coercitiva só tende a beneficiar aqueles setores que têm condições e, sobretudo, interesse econômico de induzir distorções nos resultados e se mostrar relativamente atraentes ao mercado consumidor.

Outro aspecto a ser considerado é a padronização forçada que, ao tomar por base os currículos mínimos, desconsidera as diferenças regionais e as peculiaridades específicas de cada modalidade de curso (Vianna, 2003). Com isso, as instituições de ensino superior passam a pautar seu currículo não pelas necessidades sociais e sim em razão do programa do exame, induzindo as instituições a ensinar somente aquilo que cai na prova e maneiras de obter bons resultados. A única diferença neste caso é que o "interessado direto" era a instituição e não o aluno, pois era a ela que se atribuía uma nota e esta tinha conseqüências, fossem elas as punições previstas em lei (raramente cumpridas), fossem aquelas relacionadas à disputa de mercado.

Além disso, a existência do ENC como instrumento único de avaliação do ensino superior sempre foi muito questionada. Embora no 
discurso oficial o ENC fosse apenas um dos instrumentos para a avaliação das instituições, na prática ele se confirmou como o único instrumento de avaliação. José Dias Sobrinho, discutindo essa questão, diz:

"As minhas considerações sobre o Provão certamente seriam muito diferentes se esse exame nacional estivesse fazendo parte organicamente de um conjunto integrado de avaliações, ou seja, de um programa com princípios, objetivos, agentes $e$ ações que realmente viessem a articular e combinar distintos procedimentos e processos avaliativos voltados à transformação e à melhoria da qualidade educacional. Nenhuma avaliação isoladamente pode dar conta de uma realidade tão complexa como é a educação superior." (Dias Sobrinho, 2000, p. 156-157)

Dias Sobrinho não descarta a necessidade de avaliação, mas sim a utilização do ENC como o único ou o principal sistema de avaliação das instituições. Ele aponta diversos aspectos fundamentais que foram deixados de lado com a adoção do Provão. O principal deles é que, fixandose no produto que supostamente pode ser mensurado pelo desempenho em uma prova, o exame ignorava dimensões que por sua natureza exigiriam um procedimento mais refinado de avaliação:

"A formação fica reduzida à demonstração de elementos simples do conhecimento ou de habilidades desejadas, que possam caber na métrica de um instrumento, deixando de lado a complexidade do fenômeno educativo, que comporta dimensões filosóficas, políticas, sociais, psicológicas, éticas etc. Estas dimensões não podem definir-se de um modo pré-especificado em termos de comportamento, como seria necessário para serem incluídas nas provas de rendimento." (2000, p. 136)

Outra crítica contundente refere-se à utilização dos conceitos $\mathrm{A}, \mathrm{B}$, C, D, E, os quais favoreceram o falseamento da realidade, pois o fato de tais conceitos serem atribuídos por comparação entre os cursos acarretava que a amplitude entre a menor e a maior nota para um conceito em uma área era maior ou menor que em outras (Rothen, 2003). Nas primeiras edições do ENC, o critério utilizado para a interpretação dos resultados era o de percentuais fixos para a atribuição dos conceitos. As notas eram transformadas em conceitos da seguinte forma: $12 \%$ das instituições com melhor desempenho obtinham o conceito A, as $18 \%$ seguintes, B, as $40 \%$ seguintes, C, as $18 \%$ seguintes, D, e as últimas, E. Para Rothen, a utilização dos conceitos também favorecia uma maquiagem da realidade:

"A adoção da nota média dos cursos como referência para comparar o desempenho dos cursos, em lugar da melhor nota da área, mostra que a performance na prova é discrepante nas diversas áreas. Por exemplo, em 1999 
era necessário na área de Odontologia ter-se um desempenho de $92 \%$ do curso mais bem avaliado nessa área para obter o conceito ' $A$ ', enquanto na área de Matemática, para obter esse mesmo conceito, era suficiente ter-se um desempenho de $57 \%$ do melhor curso avaliado nessa área. Nesse mesmo ano, o curso com o pior desempenho na área de Odontologia teve desempenho de $52 \%$ do melhor curso dessa área, enquanto o curso com o pior desempenho na área de Matemática teve desempenho de $11 \%$ do melhor curso dessa área." (2003, p. 119)

De forma simples, pode-se dizer que, independentemente da qualidade dos cursos, sempre uma certa quantidade deles obteria o conceito A, sugerindo por meio disso uma excelência não necessariamente verdadeira.

No ano de 2001, o critério utilizado tomou como base a média geral e o desvio padrão. A adoção desse critério mudou um pouco o quadro descrito acima, quando os conceitos foram atribuídos com os seguintes critérios:

A: Desempenho acima de um desvio-padrão da média;

B: Desempenho no intervalo entre o meio e um desvio padrão acima da média;

C: Desempenho no intervalo de meio desvio padrão acima e abaixo da média;

D: Desempenho no intervalo entre meio e um desvio padrão abaixo da média;

E: Desempenho abaixo de um desvio-padrão da média.

Com isso, seria possível haver, por exemplo, apenas conceitos $C$. Neste caso, não se estaria atribuindo A para um curso de baixa qualidade e a distorção, aparentemente, seria menor. $\mathrm{Na}$ verdade, porém, a distorção continuaria, tendo apenas mudado de forma. Se todos os cursos fossem de qualidade aproximadamente igual (supondo evidentemente que o ENC realmente mede qualidade), fosse ela ruim, fosse excelente, por esse critério todos receberiam menção $C$.

Faltaria, segundo Vianna (2003, p. 31), o estabelecimento de "uma nota de corte, que refletisse um nível mínimo de competência desejável". O Provão, da forma como foi divulgado, transformava uma medida comparativa em medida absoluta e, o que é pior, não atribuía significado de avaliação a essas medidas, uma vez que não adotava critérios mínimos de qualidade que diferenciassem o desejável do não-desejável. Uma questão importante levantada por Dias Sobrinho sobre o sistema de avaliação do ensino superior diz respeito à distinção conceitual: 
"[...] medir não é a mesma coisa que avaliar, é apenas uma parte de um processo muito mais amplo, um procedimento isolado não é, em si, um programa formativo, este também processo bastante mais amplo. O Exame Nacional de Cursos, vulgo Provão, tem fortes efeitos na política educacional superior, efeitos obviamente discutíveis, mas, sem dúvida, importantes para os objetivos propostos; porém, ele mesmo não se insere em nenhum programa formativo." (2000, p. 136)

O ENC cumpria, no entanto, uma função de cunho administrativo e político: elemento de informação para reconhecimento, credenciamento, recredenciamento ou descredenciamento de instituições e cursos. Porém, as informações das avaliações nem sempre se configuraram como subsídios para a definição de políticas de aperfeiçoamento do desempenho acadêmico. Como eram feitas ao final dos cursos, não era possível aproveitá-las na perspectiva de educação permanente, porque não se levavam em conta "nem as condições individuais de partida nem tampouco as diferenças entre as condições de produção das instituições" (Dias Sobrinho, 2000, p. 166).

Ademais, a não-captação dos conhecimentos agregados, a nãoconsideração das diferenças de produção das instituições e o alto custo da administração do exame (aproximadamente $\mathrm{R} \$ 30$ milhões/ano), em razão do crescente número de instituições, cursos e áreas, colocaram a eficiência do ENC em questão.

Com a eleição do presidente Luiz Inácio Lula da Silva, as críticas apresentadas ao ENC tiveram algum eco, mas não romperam com alguns dos eixos do modelo do Provão, como se verá a seguir. A nova proposta para avaliação da educação superior - Sinaes - tem como pressuposto inicial discutir um novo modelo de avaliação, a partir de uma articulação entre a concepção do Paiub e a concepção do ENC.

\section{SISTEMA NACIONAL DE AVALIAÇÃO DA EDUCAÇÃO SUPERIOR}

No contexto das discussões sobre a avaliação do ensino superior nos últimos 20 anos, dado o caráter que a avaliação de sistema adquiriu após as experiências realizadas no governo do ex-presidente Fernando Henrique Cardoso, o Sinaes é proposto como tentativa de organizar um sistema de avaliação capaz de combinar uma perspectiva formativa e emancipatória que vise a melhorar a qualidade de ensino e regular a expansão do ensino superior por parte do Estado. 
O documento intitulado Sinaes (Brasil, 2003) foi elaborado por uma comissão de professores de diversas universidades brasileiras, representantes do Inep, da SESu, da União Nacional dos Estudantes (UNE), que ouviu dezenas de entidades em audiências públicas. O texto final serviu como referência básica para a formulação da Lei $n^{\circ} 10.861$, de abril de 2004, que instituiu o Sinaes em substituição ao ENC.

Como vimos, a avaliação da educação superior realizada no governo do ex-presidente Fernando Henrique Cardoso estava centrada, principalmente, nos resultados, ou seja, visava à verificação da produtividade e da eficiência por meio do controle de desempenho com base em um padrão estabelecido. Portanto, diferentemente do Paiub, cuja concepção centrava-se em uma visão formativa e emancipatória, o Provão baseava-se em uma visão eminentemente regulatória. Pretendendo superar a concepção de avaliação centrada em resultados, o documento intitulado Sinaes buscou sintetizar, a partir de uma análise histórica da avaliação do ensino superior e do papel da universidade no desenvolvimento da sociedade brasileira, uma proposta que objetivasse articular regulação e avaliação educativa.

Tendo como referência uma análise das experiências de avaliação do ensino superior no Brasil, a comissão que elaborou o Sinaes concluiu que

"[...] as avaliações somativas, os mecanismos de controle, regulação e fiscalização e a prestação de contas têm tido presença muito mais forte que as avaliações formativas, participativas, voltadas aos processos, às diversidades identitárias e à complexidade das instituições." (Brasil, 2003, p. 14)

A comissão julgou necessária uma mudança na concepção de avaliação, sintetizando em quatro pontos as questões que, segundo sua análise, deveriam ser revistas na elaboração de uma nova proposta de avaliação da educação superior, pois eram características que desequilibravam a avaliação, cunhando-lhe um caráter mais regulatório que emancipatório. Nesse sentido, segundo o documento elaborado pela comissão, a proposta:

“a) está centrada quase que exclusivamente nas atribuições de supervisão do MEC;

b) praticamente não considera instituições e cursos como sujeitos da avaliação;

c) não distingue adequadamente supervisão e avaliação, com nítida ênfase à primeira; 
d) não constitui um sistema nacional de avaliação, porém, mais propriamente uma justaposição de verificação de determinadas condições, unilateralmente definidas pelo Ministério." (Brasil, 2003, p. 20)

Visando à superação dessas características presentes principalmente no ENC, a comissão propôs que a avaliação não tivesse um fim em si mesma, mas que fosse parte de um conjunto de políticas públicas visando à expansão da educação superior, cuja qualificação deveria estar vinculada à sua revalorização, com o propósito de construção de um projeto de desenvolvimento da nação brasileira.

"[...] um sistema de avaliação com autonomia, que é própria dos processos educativo-emancipatórios, e as funções de regulação, que são inerentes à supervisão estatal, para o fortalecimento das funções e compromissos educativos."

(Brasil, 2003, p. 81)

Para isso, duas idéias básicas nortearam a formulação apresentada pela Comissão Especial de Avaliação (CEA): as idéias de integração e de participação. Nessa perspectiva, o Sinaes busca garantir a integração das dimensões interna e externa, somativa e formativa, particular e global, quantitativa e qualitativa, articulando concepções, metodologias, conteúdos, práticas, agentes da comunidade acadêmica e instâncias do governo (Brasil, 2003). Os princípios que nortearam o Sinaes foram assim apresentados pela comissão:

"Justiça, rigor, efetividade, integração, globalidade, participação, eficácia formativa, efetividade social, flexibilidade, credibilidade, legitimidade, institucionalidade, continuidade, respeito à identidade institucional, sistematização. [Tais princípios devem ser articulados com] uma ampliação dos âmbitos, objetos, procedimentos e instrumentos de avaliação para além dos atualmente praticados, procurando sempre assegurar a integração, a participação, a globalidade, a relevância científica e social, a articulação da regulação com a emancipação, do institucional com o sistêmico. Tendo em vista essencialmente melhorar o cumprimento da responsabilidade social e científica das instituições em particular e da Educação Superior em seu conjunto." (Brasil, 2003, p. 91-92)

Tendo como perspectivas esses princípios e critérios, embora com mudanças em relação ao relatório original, o Sistema de Avaliação do Ensino Superior foi oficialmente instituído por medida provisória em dezembro de 2003. O texto da referida medida foi aprovado sem muitas alterações sob o número 10.861 em abril de 2004.

Há neste procedimento uma questão de fundo que mereceria ser discutida, qual seja a pertinência do uso de medida provisória para uma 
matéria desse tipo, quando a Constituição Federal, em seu artigo 62, define que, "Em caso de relevância e urgência, o presidente da república poderá adotar medidas provisórias, com força de lei, devendo submetê-las de imediato ao Congresso Nacional [...]" (Brasil, 1999). Certamente a temática da avaliação no ensino superior é relevante; porém, não parece exigir um disciplinamento unilateral do Executivo em pleno mês de dezembro. É interessante e provocativo lembrar que o uso abusivo de medidas provisórias era uma das críticas que a oposição fazia ao modo de governar do ex-presidente Fernando Henrique Cardoso.

Apesar dessa forma estranha de lidar com a regulamentação dessa matéria, é fato que as expectativas em torno do texto final aprovado e de suas possibilidades na implementação de uma concepção mais formativa de avaliação estão postas desde a instalação da comissão especial que estudou o tema. Como já se discutiu anteriormente, interessa agora apresentar o texto aprovado, procurando indicar avanços, limites, silêncios e possibilidades.

\subsection{A Lei ${ }^{\circ}$ 10.861/04}

Merece destaque, inicialmente, o fato de que a lei aprovada, no artigo $1^{\circ}$, mantém a avaliação do desempenho dos alunos como uma das três dimensões do processo avaliativo. Criam-se, então, duas outras dimensões, a avaliação de cursos e a avaliação das instituições. Apesar de no modelo anterior existirem também outros processos de avaliação, além do desempenho dos alunos, já indicamos que estas ficaram, na prática, secundarizadas.

Entre as finalidades do novo sistema de avaliação, está a melhoria da qualidade das instituições e a orientação da expansão da oferta. Essa articulação entre qualidade e quantidade pode ser um avanço no sentido de instituir um sistema de avaliação que de fato sirva ao planejamento da ação governamental, principalmente em um nível de ensino em que a expansão tem ocorrido sob a vontade do mercado. Aparentemente, este contexto de expansão interessada leva à incorporação, na concepção da lei, da necessidade de respeito à diversidade de IES existente. Tal cuidado, certamente, é necessário em um processo de avaliação que pretenda assumir um caráter diagnóstico; entretanto, caberia perguntar até que ponto essa ênfase na diversificação e no respeito às diferentes naturezas institucionais não poderá contribuir para um aprofundamento da diferença entre instituições de ensino e instituições que articulam ensino, pesquisa e extensão. $\mathrm{O}$ aprofundamento dessa diferenciação não significa um 
decorrente aprofundamento da desigualdade de acesso, ou seja, que parte dos alunos tenha acesso a um ensino superior de ponta, articulado de fato aos "níveis mais elevados do ensino, da pesquisa e da criação artísticas" (Brasil, 1999, art. 208, inciso V), enquanto a maioria tem acesso, no máximo, a uma boa qualificação profissional.

$\mathrm{O}$ artigo $2^{\circ}$ da Lei $\mathrm{n}^{\circ} 10.861$ indica, como princípio para o sistema de avaliação, o "caráter público de todos os procedimentos..." (Brasil, 2004). Tal princípio pode conceber que a avaliação do ensino superior se faça no âmbito da esfera pública. Publicizar tal debate potencialmente permite que o direito ao ensino superior, a função da universidade e o investimento que a sociedade está disposta a fazer nessa universidade sejam, também, discutidos pela comunidade acadêmica e, principalmente, pelo conjunto da sociedade. Articulada a isso está a necessária "participação do corpo discente, docente e técnico-administrativo das instituições de educação superior, e da sociedade civil, por meio de suas representações" (Brasil, 2004, art. $2^{\circ}$ ), como condição precípua para a democratização do debate. A idéia da participação como uma das diretrizes para um sistema nacional de avaliação já estava indicada no documento elaborado pela Comissão Especial e foi mantida na forma de princípio, na lei.

O caráter de regulação da qualidade do ensino superior, colocada à disposição da sociedade na sua forma pública e privada, é reafirmado pela lei uma vez que o credenciamento e o recredenciamento de cursos e instituições ficam submetidos ao Sinaes. A lei assegura que do processo de avaliação resultem medidas objetivas de melhoria de qualidade mediante $o$ que chama, no artigo $10^{\circ}$, de Protocolo de Compromisso. Tal instrumento será assinado entre o MEC e as IES que tiverem resultados insatisfatórios ao longo do processo. O descumprimento dos compromissos aí firmados é que levarão a medidas punitivas como:

\footnotetext{
"I - suspensão temporária da abertura de processo seletivo de cursos de graduação;

II - cassação da autorização de funcionamento da instituição de educação superior ou do reconhecimento de cursos por ela oferecidos;

III - advertência, suspensão ou perda de mandato do dirigente responsável pela ação não executada, no caso de instituições públicas de ensino superior." (Brasil, 2004)
}

Evidentemente, fica assegurado amplo processo de defesa às IES. Tal procedimento é legítimo; entretanto, parece-nos significar que a eficácia desse processo para punir as diversas irregularidades que decorrem da expansão privada e pautada na lógica do mercado a que o ensino superior esteve e está submetido demandará controle social sobre este processo. 
O funcionamento do processo de avaliação articula três dimensões, como já dissemos. Quanto à primeira, afirma a lei:

"Art. $3^{\circ}$ A avaliação das instituições de educação superior terá por objetivo identificar o seu perfil e o significado de sua atuação, por meio de suas atividades, cursos, programas, projetos e setores, considerando as diferentes dimensões institucionais [...]." (Brasil, 2004)

$\mathrm{O}$ artigo $3^{\circ}$ continua, em seus diversos parágrafos, com o que poderíamos chamar de indicadores para orientar o processo. Apesar de a indicação de critérios para a avaliação ser fundamental, no projeto da comissão especial eles estavam mais bem desenhados. Além do rol de elementos que deverão ser considerados na avaliação institucional, o que a lei assegurou foi que "serão utilizados procedimentos e instrumentos diversificados, dentre os quais a auto-avaliação e a avaliação externa in loco", mas sem definição de como tal processo será viabilizado. No artigo 11, a lei estabelece que, para o processo de auto-avaliação, as instituições terão 60 dias para organizar comissão própria de avaliação que articule os diferentes segmentos e que tenha autonomia institucional para conduzir o processo de avaliação interna e fornecer as informações solicitadas pelo Inep no processo de avaliação externa ${ }^{7}$.

A avaliação institucional resultará, segundo o artigo $3^{\circ}$ da lei, em uma nota para a instituição: "A avaliação das instituições de educação superior resultará na aplicação de conceitos, ordenados em uma escala com 5 (cinco) níveis, a cada uma das dimensões e ao conjunto das dimensões avaliadas" (Brasil, 1994). Não há nenhuma referência na lei a estratégias de "rankiamento" nem de premiação das instituições; no entanto, no contexto atual tal debate certamente pode ser retomado.

Quanto à segunda dimensão, não se pode dizer que ela seja propriamente uma novidade, posto que a avaliação dos cursos de graduação já vinha acontecendo como parte do ENC, tal como já se discutiu anteriormente. $\mathrm{O}$ que merece um certo destaque é que, no relatório da comissão, o ENC era substituído por um Processo de Avaliação Integrado de Desenvolvimento Educacional e da Inovação da Área (Paideia). Esse processo integrava a avaliação dos cursos e a avaliação dos alunos e indicava, pelo menos aparentemente, uma perspectiva mais ampla de diagnóstico dos cursos e da produção de conhecimento. A Lei $n^{\circ}$ 10.861/04 aprovada não tratou a temática dessa forma, mudou o nome e acabou mantendo uma forma de avaliação dos cursos e dos alunos muito

7 O MEC já instituiu a Comissão de Acompanhamento do Sinaes e vem implementando o processo. Foge do objetivo deste texto a análise destes desdobramentos. 
semelhante à forma que já vinha sendo realizada no governo anterior. Observe-se o artigo $4^{\circ}$ da lei:

"Art. $4^{\circ}$ A avaliação dos cursos de graduação tem por objetivo identificar as condições de ensino oferecidas aos estudantes, em especial as relativas ao perfil do corpo docente, às instalações físicas e à organização didático-pedagógica.

$\S 1^{\circ} A$ avaliação dos cursos de graduação utilizará procedimentos e instrumentos diversificados, dentre os quais obrigatoriamente as visitas por comissões de especialistas das respectivas áreas do conhecimento.

$\S 2^{\circ}$ A avaliação dos cursos de graduação resultará na atribuição de conceitos, ordenados em uma escala com 5 (cinco) níveis, a cada uma das dimensões e ao conjunto das dimensões avaliadas." (Brasil, 2004)

Ao que parece, não há, em relação aos procedimentos anteriores, mudanças de fundo; há mudança de forma, por exemplo, na questão da escala, que agora será de cinco níveis. Um elemento que está articulado a isso e pode contribuir para o caráter público do processo é a criação, após a aprovação do Sinaes, de uma taxa de avaliação a ser paga pelas instituições privadas quando estas solicitarem credenciamento da instituição ou do curso. Tal taxa deve custear parte do processo de avaliação. Isso parece um avanço, uma vez que, no formato anterior, as instituições pagavam diretamente as despesas das comissões de avaliação, o que, no mínimo, abria brechas para corrupção.

O terceiro componente do Sinaes, o exame de desempenho dos alunos, substitui o Provão e traz algumas novidades na sua forma de organização. O exame passa a ser denominado Exame Nacional de Desempenho dos Estudantes (Enade), não é mais anual nem é obrigatório para todos. Poderá ser feito por amostragem e será realizado a cada três anos, no máximo, em cada curso. A lei indica que o intervalo máximo é de três anos, o que significa que o MEC, por via da Comissão Nacional de Avaliação do Ensino Superior (Conaes), pode decidir por exames com mais freqüência.

Vale a pena refletir sobre duas orientações que contêm certa dubiedade nesse novo formato do exame: a primeira é a idéia de que o Enade é componente curricular obrigatório. O entendimento inicial parece referir-se ao fato de que todos os alunos terão em seus históricos a presença da sua situação perante o exame, e que todos os alunos selecionados para a amostra serão obrigados a fazer a prova; entretanto, cabe ressalva a uma possibilidade de interpretar a idéia de componente obrigatório a alguma forma de preparação para tais exames, o que seria um equívoco. Outra questão mal-explicada é o uso de resultados de desempenho dos alunos para estimular a continuidade de estudos. Dado o caráter de não- 
obrigatoriedade e a idéia de que o exame se faça sobre grupos (amostras) e não sobre o universo dos estudantes, é estranho pensar uma certa premiação aos melhores resultados, o que novamente pode criar desvios, dado o estabelecimento de expectativas entre os estudantes de que devam fazer os exames para conseguir tais estímulos.

Além dessas questões sobre a interpretação da lei, é interessante refletirmos se o Enade é realmente um mecanismo eficaz e necessário à construção de uma educação superior de qualidade. Não seriam as condições de oferecimento que deveriam ser rigorosamente avaliadas pelo Estado? Se oferecidas condições de funcionamento adequadas, a qualidade de formação dos alunos não seria (uma) conseqüência (natural) desse processo?

Por que não centrar a avaliação no acompanhamento das condições de oferecimento do ensino superior, ou seja, garantir qualidade no oferecimento, vinculando-o à melhoria da qualidade da educação básica, condição sine qua non à realização de uma educação superior de qualidade? Isso significa que, em vez de monitorar resultados e esperar que a concorrência se encarregue de elevar a qualidade da educação superior, o MEC deveria monitorar, ou melhor, acompanhar e subsidiar as condições de oferecimento do ensino superior. Isso implicaria diagnóstico das instituições; construção de estratégias de fortalecimento das IES públicas; estabelecimento de critérios de funcionamento das instituições privadas que preservassem a educação como direito individual e social. Significa que essas instituições não poderiam funcionar somente regidas pelas regras e sabores do mercado, mas teriam de se comprometer, também, com o desenvolvimento social e tecnológico do país.

Podemos dizer que o conjunto de silêncios, ou de aspectos malexplicados da lei, foram remetidos à Conaes, de certa forma uma agência reguladora das IES, pois a partir daqui caberá a essa comissão:

"[...] propor e avaliar as dinâmicas, procedimentos e mecanismos da avaliação institucional, de cursos e de desempenho dos estudantes; estabelecer diretrizes para organização e designação de comissões de avaliação, analisar relatórios, elaborar pareceres e encaminhar recomendações às instâncias competentes; formular propostas para o desenvolvimento das instituições de educação superior, com base nas análises e recomendações produzidas nos processos de avaliação; articular-se com os sistemas estaduais de ensino, visando a estabelecer ações $e$ critérios comuns de avaliação e supervisão da educação superior." (Brasil, 2004)

A composição final da Conaes aprovada na lei é bem mais interessante do que o previsto no documento da Comissão Especial. No texto da comissão, previa-se que a Conaes "será composta de 12 membros, 
entre nomes reconhecidos nacional e internacionalmente, como especialistas na área de avaliação da educação superior e, também, gestores de IES, preferencialmente com experiência concreta de coordenação ou execução de processos avaliativos e técnicos" (Brasil, 2003). Nessa definição, o que se tinha era uma espécie de grupo de notáveis que, pelo domínio técnico do processo, assegurariam sua execução. De certa forma, essa composição da comissão desconsiderava que há uma dimensão política fundamental implicada nas definições sobre a avaliação. Na lei aprovada, a Conaes deverá ser composta por:

"um representante do Inep; um representante da Capes; três representantes do $M E C$, sendo um obrigatoriamente do órgão responsável pela regulação e supervisão da educação superior; um representante do corpo discente das instituições de educação superior; um representante do corpo docente das instituições de educação superior; um representante do corpo técnicoadministrativo das instituições de educação superior; cinco membros, indicados pelo ministro de Estado da Educação, escolhidos entre cidadãos com notório saber científico, filosófico e artístico, e reconhecida competência em avaliação ou gestão da educação superior." (Brasil, 2004)

Há nesse formato previsto na lei a perspectiva de uma participação dos diferentes segmentos da comunidade acadêmica nas definições sobre o processo. O que ainda faltou, no texto legal, foi a garantia de que os diferentes segmentos pudessem eleger seus representantes ou que os representantes fossem indicados pelas entidades nacionais. A forma de escolha dos representantes de docentes, discentes e técnicos das IES ficou silenciada na lei; apenas está prevista a sua nomeação pelo presidente da República. A Conaes também deverá ser instalada em um prazo de 60 dias a contar da publicação da lei.

Enfim, temos aprovado um sistema complexo de avaliação do ensino superior que tem possibilidades interessantes de democratizar o que se fez até o momento quanto à avaliação; entretanto, tal sistema complexo não é automático e demandará a construção de novos procedimentos, principalmente no que se refere à avaliação institucional. Além disso, tal sistema ainda parece alimentar-se tanto de uma perspectiva regulatória quanto de elementos defendidos em uma perspectiva emancipatória, o que lhe confere certa ambigüidade. De forma que a aprovação da lei parece mesmo ser só mais um capítulo nessa história. 


\section{CONSIDERAÇÕES FINAIS}

Neste artigo, procuramos reconstituir a trajetória do debate sobre avaliação no ensino superior brasileiro. $\mathrm{O}$ resgate desse debate indica como a questão da avaliação é um tema antigo e marcado pela disputa entre uma concepção de avaliação sobre o produto, com vistas à constituição de uma racionalidade típica do mercado, e uma concepção de avaliação formativa, diagnóstica e que sirva ao fortalecimento da função social das instituições do ensino superior.

No caso do ensino superior, parece que discutir a avaliação sem considerar as próprias condições de oferta nesse nível de ensino é uma discussão parcial, pois definir a tarefa do Estado como regulador do sistema em um nível de ensino em que a oferta privada predomina significa a legitimação final da expansão do acesso pela via privada. Tal cenário de privatização da oferta é revelado por diferentes estudos; entre eles, o de Amaral (2003), ao analisar os dados disponíveis no Inep, demonstra que entre 1995 e 2001 a oferta de ensino superior privado subiu $97,5 \%$, enquanto a oferta pública subiu $49,2 \%$ na rede federal e $36,8 \%$ no setor público estadual. Esse aumento significa que em 2001 o ensino superior privado respondia por $69,02 \%$ das vagas, enquanto o ensino superior público, por apenas 30,98\%. Considerando que a Lei $\mathrm{n}^{\circ} 10.861 / 04$ passa a definir um complexo sistema de avaliação que propõe articular a diversidade das instituições, cada vez mais fica secundarizada a discussão acerca de que tipo de instituição se espera seja consolidada no ensino superior.

Do ponto de vista dos que defendem uma perspectiva democrática e social de educação, certamente há um consenso acerca da necessidade de as instituições de ensino serem avaliadas. Tal consenso tem relação com a necessidade de controle social sobre as instituições públicas. No que tange à iniciativa privada, o sistema de avaliação externo tem sido o único espaço de debate acerca da qualidade dessas instituições, embora até agora com pouca eficácia dos instrumentos de punição para as instituições que não têm avaliação satisfatória, como já se discutiu na apresentação do Exame Nacional de Cursos.

Esta perspectiva, de democratizar as instituições públicas pela via do controle social e do controle da qualidade da expansão do ensino superior privado, exige que os processos de avaliação se pautem em procedimentos transparentes e públicos. Tais princípios estão indicados na legislação recém-aprovada para um sistema de avaliação nacional do ensino superior, o Sinaes. 
A necessidade de os processos de avaliação serem públicos implica, também, que eles sejam de fácil publicização, algo que os exames centrados no produto conseguem rapidamente, ou seja, ao instituir provas e divulgar as notas das avaliações o processo de avaliação ganha condições de ser ampla e claramente divulgado entre a população. Este será um desafio para um sistema de avaliação mais complexo: centrar a publicização da avaliação nos processos ou nos produtos? Permitir um debate público sobre os resultados das avaliações institucionais, de cursos e de alunos, que se realize para além da nota ou do conceito atribuído ao curso/instituição, não é tarefa fácil.

A Lei $\mathrm{n}^{\mathrm{o}}$ 10.861/04 parece, nesse sentido, deixar o campo em disputa, posto que tem cuidado em estabelecer um sistema em que as diferentes dimensões do processo do trabalho no ensino superior sejam contempladas, mas, ao mesmo tempo, mantém a definição de uma escala de notas para as instituições, os cursos e o desempenho dos alunos. Se a legislação indica preocupações com o processo, não perdeu a ênfase no produto.

Articulado a isso, poder-se-ia, ainda, problematizar a continuidade da ênfase do processo de avaliação nos exames externos, ou seja, em que medida esses exames são realmente mecanismos eficazes e necessários à construção de uma educação superior de qualidade? Manter o Enade não implicará que, embora com outras intenções, o processo de avaliação do ensino superior mantenha a característica de classificar as instituições sem que de fato sejam tomadas providências em relação àquelas que oferecem condições precárias de ensino e, conseqüentemente, resultados ruins no Enade? A ênfase nos resultados dos alunos como produto do trabalho das instituições superiores não significa, mais uma vez, apostar na competição como saída para o enfrentamento da questão da qualidade na educação?

Merece, em decorrência do exposto, que nos debrucemos um pouco mais sobre o Enade, exame que substituirá o Provão e que pretende assumir uma dimensão diagnóstica, uma vez que avaliará os alunos em dois momentos distintos do curso. Cabe perguntar: será que com um exame em dois momentos dos cursos pode-se avançar a fim de permitir interpretações mais concretas acerca do desempenho dos estudantes? Será que adotar um sistema de avaliação de caráter diagnóstico não é mais do que "fotografar" mais momentos de um processo? A defesa da organização de um exame em dois momentos distintos dos cursos tem relação com a busca por identificar que nível de conhecimento o ensino superior tem sido capaz de agregar aos estudantes, pois que um único exame no final desconsidera o percurso anterior do aluno. 
Se essa tese é verdadeira, de fato precisa-se de dois momentos distintos de teste. Mas o mais importante nesse processo é que o exame do aluno não seja novamente tomado na parte. Dias Sobrinho (2000) indicava a parcialidade com que os resultados do Provão eram tomados como uma das graves limitações daquele processo de avaliação. Agora temos na legislação aprovada um tripé - avaliação institucional, avaliação de cursos e avaliação de desempenho do aluno - que pode significar uma tomada mais integrada, mais consistente para a avaliação, desde que a discussão dos resultados não se centre apenas no desempenho dos alunos.

$\mathrm{O}$ objetivo anunciado na lei que instituiu o Sinaes parece corresponder a uma perspectiva de avaliação mais complexa que se organize em ciclos, em que o início seja marcado pela auto-avaliação institucional e que, ao final, a própria instituição alimente-se do conjunto das informações geradas ao longo do processo para enfrentar seus problemas. Entretanto, insistimos para que essa idéia de processo se concretize; as partes não podem ser superdimensionadas em relação ao todo.

O segundo problema, profundamente articulado com o primeiro, é a definição do Enade como componente curricular obrigatório e a indicação de uma possível utilização dos resultados deste na destinação de incentivos para a continuidade de estudos. Como isso será feito, considerando que o exame é por amostragem? Isso pode criar uma dualidade de funções para o exame que pode supervalorizar uma das pontas do tripé e, portanto, quebrar a coerência interna do sistema de avaliação. Aparentemente, tal indicação pode vir a enfrentar o problema dos boicotes dos alunos às provas, posto que essa foi uma das estratégias de resistência dos estudantes ao caráter meritocrático do sistema de avaliação anterior. Entretanto, para enfrentar a resistência, a saída da lei é de mais ênfase à competição, agora não só entre as instituições, mas entre os alunos que realizarem as provas.

Enfim, cabe destaque para o fato de que a organização desse processo não foi completamente definida na legislação aprovada, principalmente no que diz respeito à operacionalização da avaliação institucional. O detalhamento das condições de funcionamento do Sistema Nacional de Avaliação ficou delegado à Conaes, órgão vinculado ao MEC e que terá no Inep o apoio operacional para a execução da avaliação, que apesar de ter uma composição representativa e interessante merece ser discutida em um contexto mais amplo. A instituição dessa comissão deixa a seguinte questão de fundo: por que não se voltar a discutir a representatividade do Conselho Nacional de Educação e resgatar sua tarefa de articulação de um sistema nacional de educação, nos moldes do proposto no Plano Nacional de Educação da sociedade brasileira, de forma 
que a função de definir as normas complementares do sistema de avaliação do ensino superior fique articulada nesta mesma instância?

A opção da lei é continuar a tratar essa temática de forma desarticulada do conjunto do sistema, ou, ainda, de continuar a tratar a educação nacional como uma justaposição de sistemas autônomos. Como pano de fundo parece, enfim, que se tem uma proposta de avaliação para as instituições do ensino superior que retoma a dimensão formativa da avaliação, porém, no interior de uma política educacional que nas grandes linhas ainda não rompeu com a lógica construída nos anos 1990. A eficácia de tal processo para a democratização interna e externa do ensino superior, insiste-se, dependerá do desenrolar das disputas nos próximos capítulos desta história.

\section{REFERÊNCIAS BIBLIOGRÁFICAS}

AFONSO, A. J. Avaliação educacional: regulação e emancipação. In: CATANI, A M.; OLIVEIRA, R. P. Reformas educacionais em Portugal e no Brasil. Belo Horizonte: Autêntica, 2000.

AMARAL, N. C. Financiamento da educação superior: estado e mercado. São Paulo: Cortez; Piracicaba: Unimep, 2003.

BRASIL. Constituição (1988). Constituição da República Federativa do Brasil. São Paulo: Ridel, 1999.

BRASIL. Lei $n^{\circ} 10.861$, de 14 de abril de 2004. Institui o Sistema Nacional de Avaliação da Educação Superior - Sinaes e dá outras providências. Brasília, 2004.

BRASIL. Ministério da Educação. Avaliação do ensino superior: encontro internacional. Brasília, 1988.

- Ministério da Educação. Documento básico avaliação das universidades brasileiras: uma proposta nacional. Brasília, 1993.

Ministério da Educação. Uma nova política para a educação superior

brasileira. Relatório da Comissão Nacional de Reformulação da Educação Superior, 1985. 
BRASIL. Ministério da Educação. Instituto Nacional de Estudos e Pesquisas Educacionais Anísio Teixeira. Comissão Especial de Avaliação Sinaes. Sistema Nacional de Avaliação da Educação Superior (Sinaes): bases para uma nova proposta de avaliação da educação superior brasileira. Brasília: Inep, 2003.

Ministério da Educação. Instituto Nacional de Estudos e Pesquisas Educacionais Anísio Teixeira. Seminário Avaliação da Educação Superior: a experiência do Reino Unido e do Brasil em debate. Brasília: Inep, 2001.

CATANI, A. M.; OLIVEIRA, J. F. A Reforma da educação superior no Brasil nos anos 90: diretrizes, bases e ações. In: CATANI, A. M.; OLIVEIRA, R. P. (org.). Reformas educacionais em Portugal e no Brasil. Belo Horizonte: Autêntica, 2000.

CUNHA, L. A. Reforma universitária em crise: gestão, estrutura e território. In: TRINDADE, H. (org.). Universidade em ruínas na república dos professores. 3. ed. Petrópolis: Vozes, 2001.

DALE, Roger. Globalização e educação: demonstrando a existência de uma "cultura educacional mundial comum" ou localizando uma "agenda globalmente estruturada para a educação"? Educação, Sociedade \& Cultura, São Paulo, n. 16, p. 133-169, 2001.

DIAS SOBRINHO, J. Avaliação da educação superior. In: Avaliação: políticas educacionais e reformas da educação superior. São Paulo: Cortez, 2003.

Campo e caminhos da avaliação: a avaliação da educação superior no Brasil. In: FREITAS, L. C. (org.). Avaliação: construindo o campo e a crítica. Florianópolis: Insular, 2002.

Exames gerais, Provão e avaliação educativa. In: Avaliação da educação superior. Petrópolis: Vozes, 2000.

FORRESTER, V. O horror econômico. Tradução de Álvaro Lorencini. São Paulo: Universidade Estadual Paulista, 1997.

FREITAS, L. C. (org.). Avaliação: construindo o campo e a crítica. Florianópolis: Insular, 2002. 
LEVIN, B. Reforming education from origins to outcomes. Nova York: Routledge Falmer, 2001.

OLIVEIRA, R. P. Reformas educativas no Brasil na década de 90. In: CATANI, A. M.; OLIVEIRA, R. P. Reformas educacionais em Portugal e no Brasil. Belo Horizonte: Autêntica, 2000.

ROTHEN, J. C. O vestibular do Provão. In: DIAS SOBRINHO, J.; RISTOFF, D. I. (org.). Avaliação e compromisso público: a educação superior em debate. Florianópolis: Insular, 2003.

SOUSA, S. Z. L. Avaliação e políticas educacionais: iniciativas em curso no Brasil. In: HIDALGO, A. M.; SILVA, I. L. F. (org.). Educação e Estado: as mudanças nos sistemas de ensino do Brasil e Paraná na década de 90. Londrina: UEL, 2001.

SOUSA, S. Z. L.; OLIVEIRA, R. P. Políticas de avaliação da educação e quase-mercado no Brasil. Educação E Sociedade, Campinas, v. 24, n. 84, p. 873-895, set. 2003.

VIANNA, H. M. Avaliações nacionais em larga escala: análises e propostas. São Paulo: Fundação Carlos Chagas, 2003. (Textos FCC, 23)

Recebido em: dezembro 2004

Aprovado para publicação em: janeiro 2005 
